DOSSIEE: "Vertentes da educação inclusiva".

\title{
Política de cotas, currículo e a construção identitária de alunos de Medicina de uma universidade pública ${ }^{1}$
}

\section{Quotas policy, curriculum and identity construction of medical students at a public university}

Christiane Curvelo Wickbold (i)

Vera Siqueira (ii)

(i) Fundação de Apoio à Escola Técnica do Estado do Rio de Janeiro - FAETEC, Rio de Janeiro, RJ, Brasil, chriscw11@hotmail.com

(ii) Universidade Federal do Rio de Janeiro - UFRJ, Rio de Janeiro, RJ, Brasil, verahfs@yahoo.com.br

Resumo: Este estudo está fundamentado em noções dos estudos culturais e nos
conceitos foucaultianos de saber, poder e normalização, voltado à análise de
significados construídos por estudantes de Medicina da UFRJ sobre a política de
cotas em suas possíveis relações com o currículo de Medicina e seus
desdobramentos em processos identitários. Em pesquisa com abordagem
qualitativa, caracteriza-se a cultura do curso, problematiza-se o seu currículo para
então apresentar a análise dos dados obtidos através de oito entrevistas
semiestruturadas feitas com alunos cotistas e não cotistas do mencionado curso.
Os resultados evidenciam tensionamentos nos discursos entre o "resguardo" da
tradição da UFRJ e da faculdade de Medicina, - o que dificulta transformações na
cultura e no currículo do curso - e as novas relações constituídas, propicias à
revisão de valores e do currículo, sendo os(as) alunos cotistas significados como
atores importantes em tal processo.
Palavras-chave: política de cotas, currículo, formação médica, identidades,
relações de poder

${ }^{1}$ Apoio: Conselho Nacional de Desenvolvimento Científico e Tecnológico - CNPq 


\section{pro.posıções \\ $e$-ISSN 1980-6248}

http://dx.doi.org/10.1590/1980-6248-2016-0153

Abstract: Based on cultural studies notions and Foucault's concepts on knowledge, power and normalization, this study aims to analyze the meanings constructed by the Universidade Federal do Rio de Janeiro's (UFRJ) medical students over the quota policy and its possible relations with the curriculum of medicine and with identity developments. Making use of a qualitative approach, the study characterizes the course culture, problematizes its curriculum and then presents the analysis of eight semi structured interviews with the mentioned students - quota holders and non quota holders -, highlighting tensions in their speeches between the "protection" of the traditions of UFRJ and of the medical school - which makes it difficult to change the course's culture and curriculum - and the new relationships established, conducive to a revision of values and of the curriculum, in which the quota students are signified as important actors.

Keywords: quota policy, curriculum, medical training, identities, power relations

Nas instituições, o indivíduo se depara com um conjunto de regras, valores e padrões legitimados. A Universidade é um espaço onde se reproduzem modelos desejáveis de ser e estar no mundo e, ao mesmo tempo, onde se constroem saberes, trocas e relações sociais; dentro dela encontramos teorias e práticas já instituídas, mas que, simultaneamente, estão em constante construção/transformação.

A introdução das cotas no Ensino Superior, já vigentes em algumas instituições brasileiras há mais de uma década, é bastante recente em algumas instituições federais. Para entender a abertura e/ou resistência a transformações, como as introduzidas pelas políticas de cotas, é importante contemplar as diferentes universidades como instituições com "culturas" diferenciadas -, compostas por sujeitos que compartilham valores e ideias, apesar de não estarem livres de contradições internas e de hierarquias. Da mesma forma, entendemos que existem "culturas" diferenciadas dos cursos de uma mesma universidade, que se relacionam, entre outros fatores, ao prestígio do curso na sociedade e à história da profissão.

As políticas inclusivas provocaram deslocamentos importantes nas universidades brasileiras, suscitando indagações sobre como isso é repercutido no seu ensino e no currículo. Tanto as políticas como a estrutura curricular se inserem em uma rede de relações recíprocas, mediadas pelo poder e influenciadas por mudanças sociais mais amplas, e devem ser entendidas em toda a sua complexidade. Em sua implementação, passam por ressignificações múltiplas, com desdobramentos nas relações entre os diferentes sujeitos universitários e desses com o ensino e o currículo. Também o currículo não deve ser visto tão somente como a organização curricular de disciplinas e conteúdos, mas como uma complexa rede em que se 


\section{pro.posıções \\ $e$-ISSN 1980-6248}

http://dx.doi.org/10.1590/1980-6248-2016-0153

inserem relações de poder, discursos, ideologias e relações sociais entre todos os atores de uma instituição educacional.

Fator essencial para que as políticas de ação afirmativa entrassem na agenda oficial, como aponta Schwarcz (2012), foi o surgimento, a partir dos anos 1970, de movimentos de contestação aos valores vigentes, com destaque para movimentos negros. Também foram influentes pesquisas que passaram a discutir as formas tradicionais de poder e o preconceito. $\mathrm{E}$ teve grande peso, sinaliza a autora, a realização, em 2001, sob os auspícios da ONU, da Conferência Mundial contra o Racismo, Discriminação Racial, Xenofobia e formas correlatas de intolerância, da qual o Brasil tornou-se signatário.

Em 26 de abril de 2012, foi validada por unanimidade pelo Supremo Tribunal Federal (STF) a política de cotas para garantir o acesso de negros e índios a Instituições de Ensino Superior do País, com a ressalva de que a reserva de vagas deveria levar em consideração também a condição econômica do candidato. Os ministros do Supremo Tribunal Federal reafirmaram a necessidade dessas políticas para corrigir o histórico de discriminação racial no Brasil, ressaltando o seu caráter provisório, e sua duração "o tempo necessário para corrigir as distorções", conforme destacado pelo ministro Ricardo Lewandowski, relator da ação (Ministério da Educação e Cultura, 2012).

Datam de 2002 as primeiras adesões às cotas, com pioneirismo das universidades estaduais, respaldadas por decretos estaduais. A Universidade Federal do Rio de Janeiro (UFRJ) adotou o sistema de cotas apenas a partir do ano letivo de 2011, após muita resistência, refletindo sua cultura institucional refratária a mudanças, o que não pode ser desvinculado dos modos como se efetiva seu processo de implementação. É importante notar que essa adesão se fez em relação às cotas sociais, o que é mais um exemplo da resistência enfrentada à modalidade de cotas raciais, relatada em inúmeros estudos, como no de Lima, Neves e Silva (2014). Atualmente, obedecendo às determinações do STF, em cada um de seus cursos, $50 \%$ das vagas são ocupadas na modalidade ação afirmativa e $50 \%$ na modalidade ampla concorrência (Universidade Federal do Rio de Janeiro, 2015c).

Uma vez que a preocupação com a legalidade e a constitucionalidade da ação afirmativa foi superada, pode-se avançar para debates e reflexões que venham a aperfeiçoar o sistema. Nesse sentido, parece-nos primordial conhecer melhor a "cultura" da universidade e 


\section{pro.posıções}

http://dx.doi.org/10.1590/1980-6248-2016-0153

$e-I S S N$ 1980-6248

do curso de Medicina, a dinâmica estabelecida entre os seus sujeitos, o paradigma da formação médica e as possíveis repercussões no currículo a partir da introdução dessas políticas.

No presente artigo abordamos tais questões, apresentando análise dos significados construídos por alunos de Medicina da UFRJ sobre a política de cotas em suas relações com o currículo do curso de Medicina e seus desdobramentos em processos identitários. Ressaltamos como eixo estruturante nos discursos estudantis a relação formulada entre currículo e demandas sociais, de forma articulada ao elo estabelecido entre "novas identidades" - dos(as) cotistas - e suas possíveis implicações para mudanças curriculares.

\section{A Universidade Federal do Rio de Janeiro e o seu curso de Medicina: uma cultura de tradicionalismo e de elitismo}

O elitismo e a fragmentação que marcam a Universidade Federal do Rio de Janeiro (UFRJ) não podem ser subestimados, se quisermos nos aproximar da dinâmica das suas relações de poder. Encontramos publicado no site da UFRJ (Universidade Federal do Rio de Janeiro, 2015a) depoimento do primeiro reitor da UFRJ, professor Ramiz Galvão, em documento encaminhado ao Ministro, apontando para a gênese da criação dessa instituição, marcada por fragmentações de várias ordens; o que já então a caracteriza como "retardatária, fragmentária, patrimonialista e elitista”.

A implantação dessa instituição, fundada em 1920, decorreu da justaposição de instituições de ensino superior já existentes: a Escola Politécnica, a Faculdade de Direito e a Faculdade de Medicina, tendo essa última sido criada em 1808, pelo príncipe regente D. João, com o nome de Escola de Anatomia, Medicina e Cirurgia. (Universidade Federal do Rio de Janeiro, 2015b).

Confirma a resistência dessa instituição à mudança sua demora de aproximadamente 20 anos para aderir à estrutura departamental introduzida pela reforma de 1946. Até meados dos anos 1970, a UFRJ ainda tinha sua estrutura baseada no regime de cátedra vitalícia (Universidade Federal do Rio de Janeiro, 2015a).

Apesar da inegável qualidade acadêmica dos cursos da UFRJ - principalmente no ensino e na pesquisa, haja vista que a extensão apenas nos últimos anos ganha maior fôlego -, 


\section{pro.posıções}

$e$-ISSN 1980-6248

http://dx.doi.org/10.1590/1980-6248-2016-0153

suas características de origem (elitismo, autorreferência, dispersão geográfica) apenas se agravam ao longo dos anos, "por se reproduzirem em um quadro de grande heterogeneidade quanto a recursos e condições de trabalho entre suas diversas unidades constitutivas" (Universidade Federal do Rio de Janeiro, 2015a).

O discurso institucional, que "denuncia” a fragmentação e elitismo da instituição, ganha visibilidade ao ser publicado no site da universidade. Ao estabelecer uma crítica se contrapõe a uma situação vista como desfavorável, remetendo assim a outros significados sobre o papel da universidade, mais alinhados ao seu papel democratizante.

As marcas de tradicionalismo e elitismo também se fizeram sentir em relação à aceitação das cotas. Em 2004, o Conselho de Ensino da UFRJ anunciou que rejeitaria uma possível política de cotas, tendo por base resoluções das diferentes congregações, como a da Faculdade de Medicina. Matéria de Rubem Berta (2004) inclui depoimento do então diretor daquela instituição em que declara sua posição contrária às cotas, argumentando que essa medida iria aumentar o risco de precarização do ensino e a evasão no curso. Em deliberação realizada no final de julho de 2004, todos os 32 membros da congregação se opuseram à proposta de reserva de vagas na Faculdade de Medicina. Já em 2010, a aprovação das cotas sociais pela congregação foi unânime, quando essa política já havia sido aprovada pela universidade.

É possível afirmar que a Faculdade de Medicina da UFRJ é caudatária de uma forte tradição que reforça seus traços elitistas, os quais são sustentados pela própria profissão. $O$ curso de Medicina, ao longo dos anos, foi acessível a um grupo seleto de estudantes, devido à grande concorrência no concurso de ingresso e também às condições de permanência (custo elevado com material didático, turno integral, etc.). Assim, ele pode ser considerado um "curso de elite", termo utilizado pelos próprios alunos e por professores como motivo de orgulho. Esse curso recebe conceitos elevados em avaliações oficiais e é reconhecido por muitos como um dos melhores entre os das universidades federais no Brasil, o que parece influenciar a subjetivação de seus estudantes como "superiores".

O perfil dos alunos do curso de Medicina tem sido tradicionalmente de estudantes de classe média alta e de brancos. As exclusões por etnia e classe não estão apenas presentes na Faculdade de Medicina da UFRJ. Estudo feito por Ristoff (2012) mostra que, no Brasil, 


\section{pro.posıções}

$e$-ISSN 1980-6248

http://dx.doi.org/10.1590/1980-6248-2016-0153

apenas $9 \%$ dos estudantes de Medicina possuem renda familiar de até três salários mínimos. Quando se olha pelo viés dos mais ricos (mais de dez mínimos de renda familiar), percebe-se que uma pequena minoria na sociedade (este grupo representa $12 \%$ ) torna-se uma grande maioria no campus: na Medicina esses 12\% tornam-se 67\% (Ristoff, 2012).

\section{Currículo, o paradigma da formação médica e as relações de poder}

Para o historiador inglês Ivor Goodson (2007), o currículo se tornou um mecanismo de reprodução das relações de poder existentes na sociedade, visto que as disciplinas escolares não são definidas de forma acadêmica desinteressada, mas sim de acordo com o poder e o interesse de determinados grupos sociais. "As crianças cujos pais são poderosos e ricos se beneficiam da inclusão pelo currículo, e os menos favorecidos sofrem a exclusão pelo currículo" (p. 243). Essa noção pode ser extrapolada para o Ensino Superior e reafirma a importância de as políticas de inclusão virem acompanhadas de mudanças no currículo, uma vez que a própria estrutura curricular tradicional é um mecanismo de exclusão social.

Partindo da ideia de que os elementos são relacionais e se dispõem em uma rede constituída por diversas relações, assim como as políticas inclusivas dependem de outras modificações, também a organização educacional, no que se refere à estrutura curricular, depende de outras transformações mais amplas. Para Lopes (2008), "mudanças na organização curricular dependem de mudanças mais profundas nas relações sociais e culturais, e nas relações de poder, não sendo derivadas” (p. 49).

Quanto ao currículo de Medicina, um aspecto primordial é pensá-lo em relação às necessidades de saúde da população. Após mais de três décadas da criação do Sistema Único de Saúde - SUS, o alcance dos princípios de integralidade, universalidade e equidade da atenção em saúde ainda é longínquo. Podemos relacionar esse fato, ao menos parcialmente, a certa incompatibilidade de valores e objetivos de parte dos profissionais do setor de saúde em relação aos objetivos e princípios estabelecidos pelo SUS. A partir daí, faz-se necessário discutir a formação desses profissionais, situando o contexto histórico em que ela ocorre e o processo pelo qual o currículo de Medicina passou até apresentar as características atuais. 


\section{pro.posıções \\ $e$-ISSN 1980-6248}

http://dx.doi.org/10.1590/1980-6248-2016-0153

O Relatório Flexner, publicado pela Fundação Carnegie, em 1910, nos Estados Unidos e do Canadá, resultou da avaliação das escolas médicas nesses países e teve profundas implicações para a educação médica ocidental, como apontam Pagliosa e Ros (2008). Para esses autores, se por um lado esse relatório permitiu reorganizar e regulamentar o funcionamento das escolas médicas, por outro a sua ênfase no modelo biomédico, centrado na doença e no hospital, conduziu os programas educacionais médicos a uma visão reducionista.

Segundo Pagliosa e Ros (2008),

ao adotar o modelo de saúde-doença unicausal, biologicista, a proposta de Flexner reserva pequeno espaço, se algum, para as dimensões social, psicológica e econômica da saúde e para a inclusão do amplo espectro da saúde, que vai muito além da medicina e seus médicos. (p. 496)

Nessa visão, a doença é considerada um processo natural, biológico. O social, o coletivo, o público e a comunidade não contam para o ensino médico e não são considerados implicados no processo de saúde-doença. Acresce o apontamento do conhecimento científico como o único válido, mediante a observação e a experimentação. Essas ideias contribuíram muito para o fortalecimento do paradigma biomédico.

Uma crítica ao modelo de conhecimento hegemônico na medicina ocidental é feita por Foucault (2004) em O nascimento da clínica. Nessa obra, o filósofo busca compreender a racionalidade que permeou a consolidação do saber médico na modernidade. Afirma que na clínica "se encontram doenças cujo portador é indiferente: o que está presente é a doença no corpo que lhe é próprio, que não é o do doente, mas o de sua verdade” (p. 64). Todo o poder e a verdade são concentrados no conhecimento científico e/ou em quem o detém; portanto, muitos saberes que, em determinado período, eram bem aceitos pela sociedade em geral passaram a ser desqualificados, como é o caso de certas tradições culturais e da própria homeopatia, a qual se baseia em uma visão holística do ser humano.

Amoretti (2005) ressalta o desenvolvimento das ciências e das tecnologias biomédicas como fatores que influenciaram profundamente a formação médica a partir dos anos 1970, afastando o médico de práticas integrais em saúde. Se o crescente desenvolvimento da tecnologia focada em aparelhos e procedimentos tecnocientíficos, por um lado, trouxe benefícios, ao mesmo tempo não favoreceu o atendimento integral, uma vez que se assenta em procedimentos específicos e cada vez mais especializados. Também as pressões do 


\section{pro.posıções}

$e$-ISSN 1980-6248

http://dx.doi.org/10.1590/1980-6248-2016-0153

mercado de trabalho influenciam na formação do profissional de Medicina, desfavorecendo a formação do médico generalista e privilegiando o trabalho de especialistas e profissionais com enfoque biologicista, conforme sinalizado por Batista e Silva (1998). Como bem lembrado por Ceccin e Ferla (2008), os avanços da cidadania em saúde, obtidos através de lutas sociais da defesa da saúde que marcaram principalmente as décadas dos anos 1970 e 1980, encontram resistência na formação dos médicos e demais profissionais de saúde. Seria preciso privilegiar uma formação que se alinhe à "saúde como direito à vida com qualidade; saúde como direito à atenção integral, com privilégio da promoção e prevenção, sem prejuízo da recuperação e reabilitação dos estados de saúde; saúde como expressão do andar a vida” (p. 447). Os estudiosos ressaltam como fatores importantes, interdependentes nesse processo de mudança, "as relações entre mercado de trabalho, prática profissional, estrutura acadêmicoadministrativa dos cursos e prática educativa" (p. 447).

A partir dessa breve análise contextual é possível pensar nas estreitas relações entre os processos formativos e o trabalho do profissional de saúde. A despeito de inegáveis avanços obtidos nas últimas décadas, nas reflexões e nos encaminhamentos de políticas educacionais, par a par com os movimentos e políticas da área da saúde, que resultaram na reestruturação de diversos cursos, podemos afirmar que ainda muito se tem que caminhar no sentido de reais transformações. Nesse sentido, são necessárias mudanças nas relações sociais, nas relações de poder que deem lugar a transformações curriculares, incorporadas pelos sujeitos e nos discursos e nas práticas das instituições formativas desses profissionais. Novos compromissos ético-profissionais e novas posturas como cidadãos são pressupostos para que o futuro profissional esteja preparado para atuar nas modalidades assistenciais mais recentes, como é o caso do Programa Saúde da Família, sem incorrer em dicotomias correntes, tais como prevenção versus cura e promoção versus prevenção.

\subsection{Saber-poder e a construção das identidades}

Neste ponto, é importante salientar que as configurações curriculares e de ensino não são neutras, como não o são as profissionais. Lançando mão da noção de "poder disciplinar" de Michel Foucault (2004), podemos assumir os saberes como pares de estratégias de poder. 


\section{pro.posıções \\ $e$-ISSN 1980-6248}

http://dx.doi.org/10.1590/1980-6248-2016-0153

Poder que, para o filósofo (1979), se exerce relacionalmente e é produtivo, designa relações entre parceiros nas quais certas ações modificam as ações dos outros.

No início do século XIX tem lugar um novo regime de produção da verdade médica: se anteriormente a Medicina tinha como objeto a doença, vista como essência abstrata, a partir de então seu objeto recai no saber sobre o indivíduo como corpo doente. O conhecimento, nesse novo regime, decorre da observação do fenômeno físico por aquele que é o legítimo detentor do saber; através do "olhar médico"- que corresponde a um novo modo de ver - dáse uma "leitura da natureza" (Foucault, 2004, p.118), que serve de base para desenvolver os princípios gerais do funcionamento do corpo humano. A descrição daquilo que se vê, a transformação do signo em palavra, permite o acesso àquilo "que todo mundo vê sem vê-lo, e de fazer falar apenas aos iniciados na verdadeira palavra”, de forma inacessível aos que não o são, "acima do alcance da multidão" (p. 125).

A vida é medida, a partir do século XIX, pela bipolaridade do normal e do patológico. Através do poder da verdade, da potência da racionalidade e da promessa de efetividade conformam-se condutas, normalizam-se comportamentos, oferecem-se diretrizes. O médico tem poder de decisão e intervenção, direcionando o paciente sobre como deveria compreender e experienciar seu corpo. Essa regulação sobre o comportamento dos indivíduos ocorre através da introjeção do poder, da autodisciplina. (Miller \& Rose 1993, citados por Lupton, 1997). O saber, os conhecimentos e as técnicas desenvolvidos no campo da Medicina investem os médicos de autoridade, uma vez que lhes confere a capacidade de decisão, de intervenção. Segundo o filósofo e médico francês Georges Canguilhem (1978), as ciências médicas estão relacionadas ao processo de "normalização" da sociedade, que se dá pela escolarização, pela medicalização, etc., e que são correlatos do desenvolvimento de um "maquinismo industrial” crescente. Para Foucault (2008), o exercício moderno do poder é fundamentalmente da ordem da normalização.

A gênese das profissões está diretamente relacionada aos saberes constituídos em determinado contexto, e esses intrinsecamente relacionados ao poder. A relação saber-poder está presente em todas as esferas da vida, como também nas instituições educacionais. $O$ surgimento de novas profissões e o mercado de trabalho que atualmente se apresenta extremamente competitivo e exigente conduzem os atores a disputas pelo espaço social de valorização e de reconhecimento profissional na sociedade, culminando em uma permanente 


\section{pro.posıções \\ $e$-ISSN 1980-6248}

http://dx.doi.org/10.1590/1980-6248-2016-0153

disputa de poderes que fazem parte do ambiente de trabalho, a qual já se inicia nas Universidades.

A Universidade e o currículo são dispositivos com capacidade de constituir as identidades das pessoas, pois, dentro de instituições, o indivíduo se depara com um conjunto de regras, valores e padrões legitimados. $\mathrm{Na}$ sua abordagem histórica da questão da subjetividade, Foucault (2007) descarta a noção do sujeito constituinte, soberano e originário; para ele, em diferentes épocas históricas, as pessoas são transformadas em sujeitos através da construção de diferentes padrões institucionais e práticas sociais.

Quanto às práticas, é importante frisar que, para o filósofo, elas não existem fora dos discursos. No seu livro $A$ arqueologia do saber, ele define discurso como o "conjunto de enunciados que provém de um mesmo sistema de formação; assim se poderia falar de discurso clínico, discurso econômico, discurso da história natural, discurso psiquiátrico" (Foucault, 2007, p. 141). Fazendo uma aproximação com nosso estudo, podemos dizer que o discurso da Medicina constitui alunos que falam a partir do poder de que são investidos para controle do corpo humano, da "verdade" da doença e de formas de diagnosticá-la, de tratá-la. Podemos também acrescentar que suas subjetividades são constituídas pelo discurso da academia: estudantes falam uma determinada linguagem, no interior de certos rituais, práticas institucionais, jogos de poder (Fischer, 2012), como por exemplo, nos entendimentos que têm sobre "o que conta" para o ingresso em cursos elitizados como o de Medicina ou sobre como deve se estruturar o currículo e que conteúdos são relevantes para a formação de um médico.

Entretanto, os modos de subjetivação não são meras atuações passivas do sujeito; pelo contrário, eles indicam também possibilidades, (des)caminhos, fugas e subversão do próprio sujeito. Não se aponta aqui para a ideia de um sujeito livre, autônomo e soberano criador de suas condições de existência, mas para a condição de escapar dos poderes e saberes de um dispositivo, para um outro (Deleuze, 1999).

Pensar esse sujeito não soberano remete à noção de uma identidade que não é fixa, mas em constante formação e construída a partir da relação com o Outro e de relações sociais mais amplas (Hall, 2006). O grande fluxo de informações e os valores da assim chamada "pósmodernidade" possibilitam a constituição de uma identidade complexa, transitória e contraditória, constituída a partir da diferença. Para esse autor até mesmo as identidades de 


\section{pro.posıções}

$e$-ISSN 1980-6248

http://dx.doi.org/10.1590/1980-6248-2016-0153

uma mesma comunidade não estão livres de contradições internas, jogos de poder, nem da hierarquia a qual está sempre presente, configurando as relações sociais em um determinado lugar. Essa ideia concerne à noção de complexidade da construção da subjetividade.

\section{Metodologia}

Processos de subjetivação se relacionam com os discursos. De acordo com a noção foucaultiana, os discursos não apenas representam, mas também constroem a realidade e são precursores de transformações sociais. Consideramos aqui os discursos como práticas sociais, o que implica que a linguagem verbal e as outras semióticas são partes integrantes do contexto sócio-histórico e não algo de caráter puramente instrumental, externo às pressões sociais. Assim, os significados se relacionam ao poder de classes sociais, grupos étnicos e raças, e sua interpretação deve expor suas bases culturais, históricas e de poder. Nessa concepção, os discursos têm papel fundamental na reprodução, na manutenção ou na transformação das representações que as pessoas fazem das relações e das identidades com que se definem numa sociedade (Pinto, 2002).

Adotamos uma abordagem qualitativa, não visando a generalizações e orientada para a exploração, feita a partir da interpretação descritiva dos dados (Esteban, 2010). Como procedimento de coleta dos dados, realizamos entrevistas semiestruturadas com alunos e alunas do curso de Medicina da Universidade Federal do Rio de Janeiro (UFRJ). Para Minayo (1996), através desse instrumento é possível obter "um nível mais aprofundado de informações ou opiniões ... a aproximação qualitativa permite atingir regiões inacessíveis à simples pergunta e resposta" (p. 122).

Foram feitas oito entrevistas, sendo quatro com cotistas, todos do $2^{\circ}$ período, e quatro com não cotistas - dois estudantes do $1^{\circ}$ período, uma do $2^{\mathrm{a}}$ e uma do $3^{\circ}$. Chamou atenção o fato de que a distribuição geográfica das residências dos informantes não diferiu muito, e que o pai e mãe de dois cotistas completaram o curso superior. Além disso, o pai de uma aluna não cotista com doutorado; de outra não cotista, o pai com pós-doutorado e a mãe, com doutorado. Pela recente introdução das cotas na UFRJ, optamos por entrevistar alunos não cotistas dos períodos iniciais, ou seja, aqueles que ingressaram na UFRJ quando o sistema de 


\section{pro.posıções}

http://dx.doi.org/10.1590/1980-6248-2016-0153

\section{$e$-ISSN 1980-6248}

cotas já estava em vigor. Nomes fictícios são utilizados para resguardar a privacidade dos entrevistados.

$\mathrm{O}$ fato de se tratar de uma universidade que apenas recentemente aderiu ao sistema de cotas é importante para explicar a quase inexistência de outros estudos e avaliações sobre a sua implementação, que seriam valiosos para dimensionarmos os resultados obtidos. Ao mesmo tempo, isso acrescenta importância ao presente estudo.

\section{Relações entre o currículo e a sociedade, para a universidade não ficar como se fosse uma ilha de conhecimento...}

A preocupação com a relevância da formação médica não ficou restrita aos cotistas, mas se fez presente também entre os que ingressaram pelo sistema de livre concorrência, como no caso de Marcos, do $2^{\circ}$ período, que destaca o distanciamento entre conhecimento e sociedade:

Acho que até estende um pouco isso que eu falei pra Medicina, porque en acho que qualquer curso da faculdade tem uma forma de você se juntar com a sociedade. Pra universidade não ficar como se fosse uma ilha de conhecimento, de pessoas extremamente inteligentes, e que tão ali pra aprender e ficar ricas um dia. A gente tá aqui pra servir a sociedade. (Marcos, não cotista)

O discurso do aluno se alinha ao ideal democrático, que, no contexto da Educação de nível superior, tem como desafio manter seu papel de formação cívica, intelectual e moral que vai muito além da capacitação técnica e do treinamento de profissionais para serem bemsucedidos financeiramente e atenderem a interesses de empresas privadas. Nesse sentido, Giroux (2003) faz uma importante reflexão:

Em termos estratégicos, revitalizar o diálogo público sugere que os educadores devam levar a sério a importância de defender o ensino superior como uma instituição de cultura cívica, cujo propósito é educar os estudantes para a cidadania ativa e crítica. Situada dentro de um contexto mais amplo de questões relacionadas com a responsabilidade social, a política e a dignidade da vida humana, a escola deve ser defendida como um local que oferece aos estudantes a oportunidade de se envolverem nos problemas mais profundos da sociedade, de adquirirem conhecimento, habilidades e o vocabulário ético necessário para aprender como participar e moldar a vida pública. (p.68) 


\section{pro.posições}

$e$-ISSN 1980-6248

http://dx.doi.org/10.1590/1980-6248-2016-0153

O tipo de educação a que o autor se refere é de grande importância no contexto do currículo de medicina, para que aconteça a transição de um ensino focado no desenvolvimento do raciocínio anatomopatológico para a formação de uma postura reflexiva que considere aspectos culturais, sociais e econômicos do paciente e favoreça uma visão global dele. Schraiber (1997) faz alguns comentários a respeito da prática médica e da importância da interação/comunicação com o paciente, identificando as cisões efetuadas pelo médico, que resultam na desqualificação da interatividade. Ao mesmo tempo, estabelece crítica à hegemonia conferida pelo médico à autoridade científica em decisões que anulam a subjetividade e o modo de vida dos pacientes:

Mas há outra complicação que ocorre nesse procedimento. A desqualificação da interatividade em seu todo revela que traduzimos a maior autoridade científica, automaticamente, em decisão não apenas técnica, mas bio-psico-social, isto é, a decisão amparada biologicamente (na patologia) passa a ser a melhor escolha assistencial global, já que esta estaria contida no conhecimento da patologia que detectamos no doente, por meio da "conversa útil" [ênfase no original]. Assim, a assimetria na relação passa da face técnica à ética quase sem percebermos. De uma à outra, passamos do acerto técnico-científico, em nosso ato reflexivo, no julgamento do caso, para disciplinar a vida social, anulando escolhas e modo de vida do Outro (o paciente) na relação. (p. 127)

Ver o todo, considerar os determinantes maiores da saúde, são aspectos contemplados na fala de Joana, não cotista, que ressalta a importância do senso crítico para o exercício da profissão médica, ausente em sua formação:

Sim, exatamente, a pessoa precisava ser mais crítica, sabe, pra compreender melhor o paciente que ele tá tratando e a sociedade que cria aquela doença, muitas doenças que vão ser tratadas são por conta de saneamento básico que não existe, ao estresse que a pessoa é submetida, a própria violência, e as pessoas às vezes, o cirurgião tá lá tirando a bala de um paciente e nem se preocupa em saber por que ele foi baleado. É algo muito importante pro médico, e a gente não tem praticamente disciplina alguma e as poucas que têm, a maioria são eletivas, ou seja, a pessoa pode tranquilamente passar por toda sua graduação sem qualquer contato com isso. (Joana, não cotista)

O excerto anterior remete ao modelo curricular de Medicina em que, como já observado, há predominância de disciplinas marcadas pela valorização da ciência e pela intelectualização dos saberes, em detrimento de disciplinas que estimulem um olhar crítico, que considerem a história, os aspectos sociais, culturais e econômicos que influenciam na saúde do paciente. Percebendo o currículo como construtor identitário, podemos inferir que a 


\title{
pro.posições
}

\section{$e$-ISSN 1980-6248}

carência de oportunidades que aproximem o estudante e futuro profissional da sociedade pode ser um fator que contribui para a crise da assistência.

Notamos em alguns discursos a tendência a naturalizar aquilo que está dado: no caso, o currículo de medicina:

\begin{abstract}
Aham, ah sim, você [entrevistadora] tá falando do conteúdo. Ah, eu acho que o conteúdo tá... Tá certo assim, quer dizer, não tenho como julgar isso, mas eu acho que seja suficiente pro momento, né?... Porque como eu to no terceiro periodo, então não tenho nem noção. Talvez. alguém de um periodo maior saiba até te responder melhor essa pergunta....É, aceitável. É porque eu aceito muita coisa né, vou aceitando. Quando eu não gosto eu aceito também. (Isabela, não cotista)
\end{abstract}

Tal postura de não questionamento do que está dado pode ser entendida a partir do conceito foucaultiano de normalização, conforme ocorre em instituições disciplinares, como escolas, presídios e hospitais. A normalização age no sentido de sujeitar os indivíduos às normas, de formar indivíduos dóceis e úteis, impondo ora penalidades, ora prêmios, atrelados às suas atitudes e às suas opiniões. $\mathrm{O}$ discurso da meritocracia, bastante presente na instituição e, sobretudo, nos seus cursos considerados de elite, ressoa nos posicionamentos dos estudantes. A legitimidade é conferida pelo reconhecimento da excelência da universidade e, em especial de seu curso de medicina, e neste cenário favorável, questionamentos não são necessários. Como explicou Foucault (2008):

A normalização disciplinar consiste em primeiro colocar um modelo, um modelo ótimo que é construído em função de certo resultado, e a operação de normalização disciplinar consiste em procurar tornar as pessoas, os gestos, os atos, conformes a esse modelo, sendo normal precisamente quem é capaz de se conformar a essa norma e o anormal quem não é capaz. (p.75)

O tradicionalismo, importante característica do curso de Medicina, contribui para a manutenção do status quo; o saber legitimado está diretamente relacionado ao poder, que age de forma sutil em todas as relações do tecido social.

\section{Currículo e identidades}

Algumas falas relacionaram a identidade do(a)cotista às experiências, aos valores e às atitudes que trazem consigo ao ingressar no curso de Medicina. 


\section{pro.posıções}

http://dx.doi.org/10.1590/1980-6248-2016-0153

\section{$e$-ISSN 1980-6248}

Para Vanessa e Carol (ambas cotistas cursando o $2^{\circ}$ período), a experiência de vida diferenciada que os alunos cotistas têm pode contribuir para a relevância do curso de Medicina:

A gente traz, eu falo a gente porque é... tipo eu, do interior, por exemplo, a gente traz uma carga muito grande em relação à dificuldade de várias coisas, em relação à saúde, posto de saúde precário, hospital precário, então a gente pode traz̧er uma contribuição em relação a isso, pra faculdade e até pra sociedade mesmo. (Vanessa, cotista)

Carol fala de um padrão existente que pode ser modificado com o ingresso dos alunos cotistas na faculdade e faz uma crítica ao caráter elitista do curso de Medicina:

Sei lá, [o cotista] traz uma nova visão pra sala, não é só aquela elite, porque medicina federal é elite né, aí quando você vê pessoas que pô, moram não sei aonde, longe, que são de outras cidades, que estão passando perrengue pra estudar aqui, e se esforçam, sabe... muda um pouco, sabe, a nossa turma, ela é bem diferente das $M$ 's [siglas das turmas] mais altas, sabe, você sente isso, tem uma coisa que não tem nas outras, tem pobre na sala, entendeu, que não tem nas outras, e eu acho isso muito legal, que ai a faculdade fica menos elitizada né, porque se não vai ser só aquela geração, médico filho de médico, que é filho de médico, e os outros vão ficar ... você tá colocando gente que é tão boa quanto, né, [referindo-se aos cotistas] falando de aula, falando de estudo, mas que tem uma visão completamente diferente, de quem já passou pela fila do SUS, que já não foi atendido, erro médico, um monte de coisa, que gente que tá na nata da sociedade, é raro né, acontece mas é bem raro. É, acho que é bem vantajoso pro curso, né, você tá formando pessoas que conhecem o sistema, a parte ruim dele. É bem legal. (Carol, cotista)

Os excertos anteriores evidenciam a construção por parte de alunas cotistas, das diferenças identitárias entre cotistas e não cotistas e o destaque que dão a elas. No último excerto, fica claro o pressuposto estabelecido entre a origem social do(a) estudante, que abre lugar a determinadas experiências - por exemplo, no caso dos cotistas, o enfrentamento das mazelas do serviço de saúde - e a sua identidade com o compromisso e o caráter social da Medicina, atrelado a uma crítica ao modelo elitista de formação do profissional médico.

A questão da formação identitária apareceu também com referência à diferença de valores e experiências que influenciam no desempenho acadêmico do aluno no curso. As alunas relatam trajetórias difíceis para o alcance do objetivo - trajetórias que significam como mais árduas do que as seguidas pelos alunos não cotistas. Dessa forma se subjetivam como indivíduos persistentes, que lutam para alcançar suas metas e que, através desse caminho, conseguem bom desempenho na Faculdade de Medicina, até melhor do que aquele dos não cotistas. Devemos notar que é no âmbito da norma que se dão esses processos os quais, conforme observam Veiga Neto e Lopes (2007), se articulam segundo a relação 


\section{pro.posıções}

$e$-ISSN 1980-6248

inclusão/exclusão. Nesse sentido, observamos um movimento por parte dos cotistas de se encaixarem nos padrões "adequados", de se aproximarem em termos de desempenho dos não cotistas, comparando-se constantemente com eles, os "normais", a partir dos quais os primeiros - que correspondem aos "outros" - são definidos. O cotista se diz mais esforçado e afirma que o grupo tem mais conhecimento ("a gente já se mata, tem bem mais aprofundado a matéria"), e assim tenta apagar as diferenças colocadas pelo estabelecimento de relações hierárquicas, socialmente definidas:

A gente tá se matando de estudar, mas é aquilo que a gente sempre quis. A gente batalhou, conquistou e agora a gente vai até o fim, pra conseguir o melhor possivel, aproveitar de todas as formas. Que nem eu vejo, que nem algumas pessoas que eu vejo que conseguiu porque parece que teve oportunidade e tudo, então não levam tão a sério, foi mais fácil pra eles. Então eles aproveitam bastante a vida, né, do que a gente que acaba não aproveitando. Mas você vê que eles só têm o conbecimento pra fažer a prova e eles não têm mais nada por fora. A gente já se mata, tem bem mais aprofundado a matéria, a gente sabe... Não é... Puxando nosso saco, mas a gente se dá melhor, digamos... E sei lá... É bom... (Augusto, cotista)

Outro aluno cotista faz referência a uma aluna, considerada uma das mais nerds ${ }^{2}$ da turma e que é cotista, reforçando a mencionada relação. Observamos uma estratégia de homogeneização, de inclusão na norma, na medida em que se prova "alguma coisa para alguém":

Uma das mais nerds da turma é cotista. Parece que não é só pra provar alguma coisa pra alguém, mas tem um empenho maior, assim, porque às vez̧es tá aqui e não tem aquela condição de estar aqui e fica pensando, poxa eu tenho que fazer valer a pena esse esforço. Acho que a gente [cotistas] valoriza mais. (Bruno, cotista)

O mesmo aluno destaca que a diversidade cultural proporcionada pela recente mudança na forma de ingresso na Universidade contribui para a formação profissional do médico, na medida em que facilita o desenvolvimento da habilidade de se relacionar com "o diferente":

O pessoal das outras turmas tem um poder aquisitivo maior, e a nossa turma hoje, você vê que é um pessoal de classe média, de classe mais baixa, entende, ai você vê a diferença, porque quando tem uma turma mais misturada, de pessoas de "status" diferente assim, você sente, você vê aquele compartilhamento de experiência, ah minha experiência de vida é essa, a minha é essa, ab eu sou da zona sul, ab eu sou de uma comunidade assim, então você vê aquela diferença. Então, eu acho que o profissional não é só o currículo, então ele vai desenvolver essa forma de lidar com pessoas diferentes, entende? Então eu acho que isso vai valer não só para o curriculo, mas na formação profissional dele, como um médico que vai lidar com pessoas, entende? (Bruno, cotista)

\footnotetext{
${ }^{2}$ Anglicismo, que significa uma pessoa que estuda muito e consegue boas notas.
} 


\section{pro.posıções \\ $e$-ISSN 1980-6248}

http://dx.doi.org/10.1590/1980-6248-2016-0153

Fica evidenciada uma visão de currículo que se alinha à preocupação sobre os seus efeitos, o currículo como construtor identitário: no convívio entre alunos de diferentes classes sociais, processos formativos importantes ocorrem relacionados a uma abertura para a diferença, de aceitação do(a) outro(a). É estabelecida uma relação desse tipo de experiência com a prática profissional que requer que o médico esteja capacitado para lidar com pessoas "diferentes".

Entretanto, a multiplicidade de discursos sobre a política das cotas remete a pensar também sobre como essa diferença é, às vezes, concebida como desestabilizadora de um ordenamento social visto como ideal; e faz-nos refletir sobre de que forma o conhecimento serve para diferenciar grupos sociais e para reforçar o domínio do estatuto da Medicina, resistente a mudanças e elitizado:

A diferença da cota para não cota é absurda, sabe? [Referindo-se à nota de corte para ingresso]. E poxa, a pessoa às vezes, não é nem pela questão de entrar, é pela questão de se manter, não conseguem se manter na faculdade também. Não querendo discriminar, não sou preconceituosa, mas às vezes eles nem conseguem se manter na faculdade, não conseguem acompanhar as aulas, então também deixa de... de... aju... privilegiar alguém que poderia... (Isabela, não cotista)

No excerto anterior, verificamos uma generalização do "outro diferente" que não tem condições "para se manter", carece de conhecimento e/ou é intelectualmente inferior em relação aos não cotistas. Assim, estabelece-se uma construção hierárquica, ao fixar posições a serem ocupadas pelas identidades subalternas - que não se adéquam às "normas" - e pelas hegemônicas, correspondentes às "naturais", às "desejáveis", conformes à "norma". De forma que se quer neutra e objetiva - a aluna se caracteriza como não preconceituosa -, lançase mão como justificativa para o que significa como uma injustiça em relação aos não cotistas - "alguém que poderia", - a presença de alunos(as)que não têm possibilidades de se manter, de "acompanhar as aulas". Essa fala pode ser relacionada a embates entre classes, entre culturas, em contextos sociais nos quais se identifica o risco de perda de privilégios, no caso uma vaga em um curso muito disputado de uma universidade federal. É possível também ter como hipótese sua contraposição a uma heterogeneização cultural, a qual força uma aproximação dos(as) "de fora" com os que "podem", que merecem estar “dentro". Nessa fala, os valores da diferença conhecimento do outro, de suas experiências, valorizada, por exemplo, na fala do estudante cotista Bruno - não ganham destaque positivo. Notamos também que é silenciada a questão 


\section{pro.posıções \\ $e$-ISSN 1980-6248}

de dar condições aos cotistas para que permaneçam no curso, através, por exemplo, de reforço acadêmico.

O contato mantido com o antes desconhecido, o aluno cotista, é também significado, dessa vez positivamente, como algo que precipita mudanças na forma de ver a política de cotas e de se posicionar em relação a ela. Nessa argumentação, a aluna Amanda (não cotista) se constrói como alguém que, pela observação e pela experiência, passa a ocupar um lugar de sujeito mais favorável à política de cotas. O ingresso na faculdade e o contato com os alunos cotistas contribuíram para que ela desmitificasse certas ideias recorrentes em relação a essa política.

Fora, quando eu tava de fora eu era contra, só que hoje eu vejo que é meio que mito, isso que falam, que os cotistas puxam pra baixo o rendimento da sala e isso en fui perceber agora, agora só, aqui agora com a sua pergunta. (Amanda, não cotista)

A hipótese sobre possíveis transformações nas formas de se perceberem as cotas, como sugere o depoimento de Amanda, no contexto de convívio entre estudantes cotistas e não cotistas, tem sido objeto de discussão em estudos recentes como o de Lima, Neves e Silva (2014), o qual problematiza o posicionamento de alunos diante das cotas raciais e sociais, antes e depois de sua implementação, em uma universidade federal.

Questionada sobre o momento que marcou essa mudança de visão sobre as cotas, a aluna afirmou que foi justamente durante a entrevista; assim, notamos que nesse processo se efetivou uma ressignificação de sua visão sobre as cotas. Falas recorrentes, muitas vezes utilizadas a partir de mera repetição, sem evidência suficiente para se sustentar, como por exemplo, a forte presença da ideia de que as cotas baixariam a qualidade do ensino, ainda assim são frequentemente defendidas como argumento contrário às cotas, como apareceu em algumas falas no presente estudo. Consideramos que nesse caso a aluna teve oportunidade de enxergar aspectos que não estavam claros anteriormente. À medida que se expressava, ao procurar argumentos e interagir com a entrevistadora, outras formas de perceber a questão foram surgindo:

Olha, se en fosse assim... [pausa, pensando] eu sei que não é a solução certa, mas se eu fosse, por exemplo, uma historiadora, por exemplo, daqui a 50anos, olhando pra essas duas últimas décadas sabe, que são das cotas, en acharia que o resultado vai ser positivo. Eu acho. Apesar dos pesares, das polêmicas de agora... (Amanda, não cotista) 


\section{pro.posıções \\ $e$-ISSN 1980-6248}

http://dx.doi.org/10.1590/1980-6248-2016-0153

O discurso de Amanda chama atenção para o momento em que ela passa a questionar certas ideias, o que nos leva a pensar sobre a importância de discussões e reflexões a respeito de temas referentes à inclusão social.

\section{Considerações finais}

Os resultados da pesquisa evidenciaram tensionamentos nos discursos entre a tradição da UFRJ e da sua Faculdade de Medicina- que influenciam de forma a manter o currículo com ênfase tecnocientífica e na cultura da meritocracia - e as novas relações sociais constituídas com o ingresso de estudantes provenientes de camadas menos favorecidas pela política de cotas. Se, por um lado, percebemos posturas voltadas ao apagamento das diferenças e à defesa dos interesses individuais, também identificamos discursos alinhados ao ideal democrático de inclusão social. Práticas divisórias foram evidenciadas nas subjetividades aqui descritas e analisadas, na medida em que atuam tanto para preservar o status do curso de Medicina e o seu currículo, protegendo-os de uma suposta "degeneração", como para alterá-los sob a forma do discurso de inclusão. Subjetividades complexas, cuja resistência às mudanças talvez se relacione ao cuidado com o "resguardo" da configuração da clínica, que continua a "herborizar no campo do patológico" (Foucault, 2004, p. 97) e que se assenta em um olhar médico que "não é mais o olhar de qualquer observador, mas o de um médico apoiado e justificado por uma instituição, o de um médico que tem poder de decisão e intervenção" (p. 97).

Um achado importante, ao qual demos relevo neste artigo, foi a significação pelos alunos cotistas de que as mudanças introduzidas a partir do ingresso de jovens anteriormente excluídos, oriundos de estratos menos privilegiados da população, têm o potencial de alterar de forma significativa as relações entre os alunos, entre os professores e os alunos, nas suas identidades, nas práticas de ensino e no conteúdo curricular. Obtivemos também indícios de que, para se adequar às normas, eles estão se construindo como um grupo diferenciado de alunos mais aplicados e persistentes em relação aos não cotistas.

Temos por hipótese que a construção histórica e social da Medicina como primeiro saber da área de saúde reconhecido cientificamente constitui empecilho para mudanças curriculares mais profundas e é internalizada em posicionamentos e práticas desses estudantes, 


\section{pro.posıções \\ $e$-ISSN 1980-6248}

http://dx.doi.org/10.1590/1980-6248-2016-0153

subjetivando-os, por exemplo, ao não questionar o caráter biomédico e pouco crítico de sua formação, naturalizando aquilo que está dado.

A presença de pensamentos renovadores e a possibilidade de movimentos transformadores fazem parte de um processo em que políticas devem ser integradas, e discussões realizadas para que as mudanças nas relações de poder ocorram gradualmente e modifiquem a estrutura das relações internas no curso de medicina e de forma mais ampla na área da Saúde.

Foi possível perceber que algumas ressignificações estão acontecendo a partir do convívio com estudantes de diferentes origens sociais e regionais, que vão em direção a uma visão mais democrática da formação médica e da universidade. Nesse sentido, mereceu destaque a fala de uma aluna não cotista, na medida em que sugere que os contatos e a observação no contexto da implementação das cotas propiciaram transformações na forma de vê-las e de se posicionar diante elas. Essa relação, interessante e merecedora de maior investigação, tem sido objeto de discussão em estudos recentes como o de Lima et al. (2014), que compara posições de alunos universitários em relação à política de cotas antes e após sua implantação, encontrando um decréscimo na rejeição das cotas sociais, mas um aumento na rejeição das raciais. As cotas raciais, em nosso contexto, têm enfrentado maior objeção do que as sociais, conforme relatado em vários estudos, como em Daflon, Feres Júnior e Campos (2013), que com propriedade sinalizam para a resistência de alguns setores da sociedade brasileira em admitir a modalidade das ações afirmativas raciais, considerando tratar-se de um país o qual teve, por um longo período, como um dos seus pilares identitários, a ideia de "democracia racial". Com base nos dados do Instituto Nacional de Pesquisas Educacionais, os autores apontam que a maioria das universidades públicas, até o ano de 2012, preferiu adotar as cotas sociais.

A nosso ver, as políticas inclusivas nas Universidades, e particularmente as cotas, podem vir a favorecer mudanças em direção à ampliação da diversidade cultural dentro do curso de Medicina, a novas relações sociais e a uma identidade mais social do currículo. É possível supor que essas políticas educacionais, além de oferecer oportunidades a uma parcela da população mais ampla, favoreceriam uma aproximação aos interesses populares e comunitários, uma vez que grupos antes marginalizados integrariam o curso e exerceriam influências do contexto social do qual fazem parte. 


\section{pro.posıções}

$e$-ISSN 1980-6248

http://dx.doi.org/10.1590/1980-6248-2016-0153

Como bem observam Veiga Neto e Lopes (2007), "igualdade de acesso não garante a inclusão e, na mesma medida, não afasta a sombra da exclusão” (p. 958). O tensionamento nos discursos dos estudantes, a evidência dos lugares sociais distintos que ocupam, o esforço relatado de os cotistas se enquadrarem nas normas, evidenciam que uma das arenas importantes para uma inclusão real ocorre no âmbito do poder, da relação entre sujeitos, dos embates que se estabelecem no cotidiano universitário. Nas brechas das redes de poder, novas formas de relacionamento e outras perspectivas vão se construindo, em um vaivém cujo percurso se dá entre progressos e recuos.

Finalizamos, chamando atenção para a importância da criação de espaços de reflexão, os quais se apresentam como uma oportunidade de desenvolvimento da capacidade crítica e reflexiva da comunidade universitária, com possíveis desdobramentos nas relações internas da Universidade e na desconstrução de "verdades" historicamente produzidas. Antevemos assim possibilidades e transformações que atualmente estão presentes no plano teórico, mas que ainda não se realizam de forma efetiva na prática.

\section{Referências}

Amoretti, R. (2005). A educação médica diante das necessidades sociais em saúde. Revista Brasileira de Educação Médica, 29(2), 136-146.

Batista, N. A., \& Silva, S. H. S. (1998). O professor de medicina. São Paulo: Loyola.

Berta, R. (2004). Medicina diz não às cotas [Reportagem]. Jornal O Globo, Rio de Janeiro.

Canguilhem, G. (1978). O normal e o patológico. Rio de Janeiro: Forense Universitária.

Ceccin, R., \& Ferla, A. (2008). Educação e saúde: ensino e cidadania como travessia de fronteiras. Trabalho, Educação e Saúde, 6(3), 443-456.

Daflon, V. T.,Feres Júnior, J., \& Campos, L. A. (2013). Ações afirmativas raciais no ensino superior público brasileiro: um panorama analítico. Cadernos de Pesquisa, 43(148), 302327.

Deleuze, G. (1999). Que és un dispositivo? In E. Balibar (Org.), Michel Foucault, filósofo (pp. 155-163). Barcelona: Gedisa. 


\section{pro.posıções}

http://dx.doi.org/10.1590/1980-6248-2016-0153

\section{$e$-ISSN 1980-6248}

Esteban, M. P. S. (2010). Pesquisa qualitativa em educação: fundamentos e tradições. Porto Alegre: AMGH.

Fischer, R. M. B. (2012). Trabalhar com Foucault. Arqueologia de uma paixão. Belo Horizonte: Autêntica.

Foucault, M. (1979). Microfísicado poder. Rio de Janeiro: Graal.

Foucault, M. (2004). O nascimento da clínica (6a ed.). São Paulo: Forense Universitária.

Foucault, M. (2007). A arqueologia do saber. Rio de Janeiro: Forense Universitária.

Foucault, M. (2008). Segurança, território, população: curso dado no Collège de France (1977-1978). São Paulo: Martins Fontes.

Giroux, H. (2003). Atos impuros: a prática politica dos estudos culturais. Porto Alegre: Artmed.

Hall, S. (2006). Identidade cultural na pós-modernidade (11a ed.). Rio de Janeiro: DP\&A.

Goodson, I. (2007). Currículo, narrativa e o futuro social. Revista Brasileira de Educação, 12(35), 241-252.

Lima, M. E. O., Neves, P. S. da C.,\& Silva, P. B. e. (2014). A implantação de cotas na universidade: paternalismo e ameaça à posição dos grupos dominantes. Revista Brasileira de Educação, Rio de Janeiro, 19 (56), 141-163.

Lopes, A. C. (2008). Políticas de integraşão curricular. Rio de Janeiro: Editora UERJ.

Lupton, D.(1997). The imperative of health. Public health and the regulated body.London: Sage Publications.

Minayo, M. C. (1996). O desafio do conhecimento: pesquisa qualitativa em saúde (8a ed.). São Paulo: Hucitec.

Ministério da Educação e Cultura (2012). Portal do MEC. STF decide por unanimidade que sistema de cotas é constitucional. Recuperado em 10 de janeiro de 2017, de http://portal.mec.gov.br/ultimas-noticias/212-educacao-superior-1690610854/17715stf-decide-por-unanimidade-que-sistema-de-cotas-e-constitucional.

Pagliosa, F. L., \&Ros, M. A. (2008). O Relatório Flexner: para o bem e para o mal. Revista Brasileira de Educaşão Médica, 32(4), 492-499. 


\section{pro.posıções}

http://dx.doi.org/10.1590/1980-6248-2016-0153

\section{$e$-ISSN 1980-6248}

Pinto, M. J. (2002). Comunicação e discurso: introdução à análise de discursos (2a ed.). São Paulo: Hacker Editores.

Ristoff, D. (2012). O espelho distorcido. Cadernos do GEA, 1(1), 9.

Schraiber, L. B. (1997). No encontro da técnica com a ética: o exercício de julgar e decidir no cotidiano do trabalho em Medicina. Interface-Comunicação, Saúde, Educação, 1(1), 123-140.

Schwarcz, L.M. (2012). Nem preto nem branco, muito pelo contrário: cor e raça na sociabilidade brasileira. São Paulo: Claro Enigma.

Universidade Federal do Rio de Janeiro (2015a). História. Recuperado em 10 de outubro de 2015, de http://www.ufrj.br/historia.

Universidade Federal do Rio de Janeiro (2015b). Faculdade de medicina: história. Recuperado em 10 outubro de 2015, de www.medicina.ufrj.br/colchoes.php?id_colchao=1

Universidade Federal do Rio de Janeiro (2015c). Acesso à graduação. Recuperado em 10 outubro de 2015, de https://ufrj.br/acesso-graduacao

Veiga Neto, A., \& Lopes, M. C. (2007). Inclusão e governamentalidade. Educação e Sociedade, 28(100), 947-963.

Submetido à avaliação em 4 de novembro de 2016, revisado em 7 de junbo de 2017, aceito para publicação em 31 de julbo de 2017. 